\title{
Variasi Dosis Pupuk Cair Lcn (Limbah Cair Nanas) terhadap Pertumbuhan Anggrek Dendrobium Sp untuk Menyusun Panduan Praktikum
}

\author{
Agus Sutanto ${ }^{1)}$, Arifah Qurniani ${ }^{2)}$ \\ ${ }^{1}$ P. Biologi FKIP Universitas Muhammadiyah Metro \\ J1. Ki Hajar Dewantara No. \\ e-mail: sutantoII@gmail.com \\ ${ }^{2}$ Pendidikan Biologi FKIP Universitas Muhammadiyah Metro
}

\begin{abstract}
ABSTRAK
Penelitian bertujuan untuk mengetahui pengaruh pemberian dosis pupuk cair oganik LCN (Limbah Cair Nanas) terhadap pertumbuhan tanaman anggrek Dendrobium sp, dan hasil penelitiannya sebagai rancangan sumber belajar Biologi SMA Kelas XII Semester Ganjil berupa Panduan Praktikum. Rancangan penelitian menggunakan penelitian Rancangan Acak Lengkap (RAL). Penelitian ini terdapat I kontrol, 3 perlakuan. Pupuk Cair LCN (Limbah Cair Nanas) dengan dosis kontrol (Oml), A (2ml), B (3ml), dan C (4ml). pupuk cair diberikan dengan cara penyemprotan menggunakan spreyer. Parameter yang diukur adalah pertumbuhan tinggi tanaman $(\mathrm{cm})$ dan pertambahan jumlah daun (helai). Hasil penelitian diuji menggunakan uji ANAVA satu jalur menunjukkan bahwa pada aplikasi pupuk cair organik LCN tidak berpengaruh secara nyata terhadap pertumbuhan tinggi tanaman anggrek $(p<0,05)$ dan pada pertambahan jumlah daun (helai) berpengaruh secara nyata $(\mathrm{p}>0,05)$. Hasil validasi panduan praktikum menunjukkan bahwa panduan praktikum yang dibuat layak untuk digunakan menjadi sumber belajar dalam proses belajar mengajar biologi pada materi Pertumbuhan dan Perkembangan.
\end{abstract}

Kata kunci: pupuk cair LCN, pertumbuhan anggrek, rancangan panduan praktikum

\section{Pendahuluan}

Limbah Cair Nanas dengan kandungan bahan organik tinggi tidak mampu diuraikan oleh bakteri diperairan atau sungai secara alami, karena volume dan kadar limbah yang tinggi, serta jumlah dan jenis bakteri yang tidak memadai di perairan, untuk itu kualitas LCN harus memenuhi standar baku mutu untuk emisinya. Salah satu teknologi pengolahan air limbah yang aman dan berwawasan lingkungan adalah menggunakan bakteri yang berpotensi pengurai. Secara alamiah untuk memperoleh bakteri yang berpotensi sebagai pengurai dapat dilakukan dengan mengisolasi limbah itu sendiri (bakteri indigen), kemudian dikultur secara murni di laboratorium secara in vitro. Bakteri indigen limbah cair nanas yang mampu menetralkan $\mathrm{pH}$, yaitu: Bacillus cereus, Acinobacter baumanni, Bacillus subtitlis dan Pseudomonas pseudomallei (Sutanto, 20II). Kandungan unsur hara dalam Limbah Cair Nanas (LCN) dapat dilihat pada Tabel I.

Tabel I Kandungan Unsur Hara LCN

\begin{tabular}{|c|c|c|c|c|}
\hline \multirow{2}{*}{ No } & \multirow{2}{*}{ Parameter } & \multirow{2}{*}{ Satuan } & \multicolumn{2}{|c|}{ Limbah Cair Nanas } \\
\hline & & & Kisaran & Rata-rata \\
\hline $\mathrm{I}$ & $\mathrm{C}$ & $\%$ & $0,0 \mathrm{I}-0,28$ & $0, \mathrm{I} 4$ \\
\hline 2 & $\mathrm{~N}$ & Ppm & $\mathrm{I}, 45-77,20$ & 26,17 \\
\hline 3 & $\mathrm{P}$ & Ppm & $3,96-88,53$ & 31,78 \\
\hline 4 & $\mathrm{~K}$ & Ppm & I5,23-689,I8 & $\mathrm{I} 34,08$ \\
\hline 5 & $\mathrm{Ca}$ & Ppm & $5,70-234,65$ & 39,53 \\
\hline 6 & $\mathrm{Mg}$ & Ppm & $2,40-27,40$ & 7,47 \\
\hline 7 & $\mathrm{Na}$ & Ppm & $32,70-3220,00$ & 474,00 \\
\hline
\end{tabular}




\begin{tabular}{lllll}
\hline 8 & $\mathrm{Fe}$ & Ppm & $2,76-92,29$ & $\mathrm{I} 6,26$ \\
\hline 9 & $\mathrm{Zn}$ & Ppm & $0,06-0,80$ & 0,47 \\
\hline $\mathrm{I} 0$ & $\mathrm{Mn}$ & $\mathrm{Ppm}$ & $0,2 \mathrm{I}-\mathrm{I} 3,60$ & 3,30 \\
\hline $\mathrm{II}$ & $\mathrm{S}$ & $\mathrm{Ppm}$ & $\mathrm{I}, 89-2452,00$ & 238,59 \\
\hline $\mathrm{I} 2$ & $\mathrm{NO}_{3}$ & $\mathrm{Ppm}$ & $0,75-\mathrm{I} 6,87$ & 3,94 \\
\hline $\mathrm{I} 3$ & $\mathrm{NH}_{4}$ & $\mathrm{Ppm}$ & $\mathrm{I}, \mathrm{I} 2-26,5 \mathrm{I}$ & $\mathrm{I3,62}$ \\
\hline $\mathrm{I} 4$ & $\mathrm{C} / \mathrm{N}$ & $\mathrm{Ppm}$ & $3,76-207,30$ & $\mathrm{I} 05,53$ \\
\hline
\end{tabular}

Sumber: Julius (dalam Sutanto, 20II)

Berdasarkan dari Tabel di atas kandungan pupuk cair Limbah Cair Nanas (LCN) dapat memenuhi kebutuhan dari unsur hara pada tanaman. Unsur hara yang dibutuhkan oleh tanaman itu dapat berupa unsur hara makro dan unsur hara mikro diantaranya adalah $\mathrm{C}, \mathrm{N}, \mathrm{P}$, $\mathrm{K}, \mathrm{Ca}, \mathrm{Mg}, \mathrm{Na}, \mathrm{Fe}, \mathrm{Zn}, \mathrm{Mn}, \mathrm{S}, \mathrm{NO}_{3}, \mathrm{NH}_{4}$, dan $\mathrm{C} / \mathrm{N}$. Limbah Cair Nanas (LCN) dengan beberapa kandungan haranya dapat dijadikan sebagai pupuk organik bagi tanaman anggrek Dendrobium sp.

Anggrek merupakan nama umum untuk menyebut semua jenis tumbuhan famili Orchidaceae (keluarga anggrek-anggrekan). Anggrek merupakan salah satu tanaman yang dipilih untuk dilakukan pembudidayaannya karena termasuk tanaman hias yang sangat prospektif dan termasuk kedalam salah satu kelompok bunga terbesar diantara bunga-bunga lainnya.

Anggrek memiliki sifat karakteristik yang lain dibandingkan bunga-bunga yang lainnya. Karakteristik anggrek ini dapat di lihat dari: besar kecil (ukuran bunga), tebal tipis bunga, kelembutan (halus) bunga, tangkai bunga dan jumlah kuntum bunga pada tangkai, ketahanan bunga (umur bunga waktu mekar) dan keharuman bunga (Lestari, 2003).

Secara morfologi, tanaman anggrek ini terdiri dari bagian batang, akar, daun, bunga dan buah. Anggrek Dendrobium sp termasuk ke dalam anggrek simpodial karena anggrek memiliki pertumbuhan yang terbatas dan memiliki rhizome sebagai sebagai batang tumbuh yang berfungsi untuk memunculkan tunas baru. Batang dari tanaman anggrek simpodial memiliki umbi semu (Pseudobulb) yang berfungsi sebagai penyimpan cadangan makanan dan air. Tanaman anggrek ini memiliki akar yang lunak dan mudah patah, bagian ujungnya meruncing, agak lengket dan licin saat dipegang. Daun anggrek muncul pada ruas-ruas batang dengan posisi berhadapan atau berpasangan. Bunga anggrek tersusun atas bagian sepal (daun kelopak bunga), petal (daun mahkota bunga), pollinia atau polen (alat kelamin jantan), putik (alat kelamin betina), dan ovari (bakal buah). Buah anggrek berbentuk kapsul (capsular) yang terbelah enam bagian (Agromedia, 2006).

Faktor-faktor yang dapat mempengaruhi pertumbuhan tanaman anggrek diantaranya seperti suhu, kelembaban dan cahaya. Anggrek Dendrobium merupakan anggrek yang banyak ditanam orang dikarenakan tanaman anggrek Dendrobium mudah untuk dirawat, mudah tumbuh, dan mudah berbunga. Lingkungan tumbuh yang ideal untuk anggrek Dendrobium yaitu suhu siang berkisar antara $27-32^{\circ} \mathrm{C}$ dan suhu malam berkisar $2 \mathrm{I}-24^{\circ} \mathrm{C}$; kelembaban $60-$ $80 \%$; cahaya matahari $55-65 \%$ atau intensitas cahaya berkisar I.500-3.000 fc (Darmono, 2004).

Lokasi penanaman anggrek harus dimanipulasi sedemikian rupa agar menyerupai iklim aslinya. Salah satu cara yang paling aktif adalah pemberian naungan atau paranet (Wagiman, 2007). Anggrek Dendrobium sp termasuk kedalam jenis anggrek suhu panas yang tumbuh didataran rendah dengan ketinggain antara 0750m dpl (Agromedia, 2006).

Agromedia (2006) media tanam anggrek dapat berupa pot tanah liat dan pot plastik, media pot yang digunakan harus banyak lubang untuk udara masuk dan keluar. Banyaknya lubang pada pot juga mampu memperlancar perputaran udara (aerasi) dan sistem pembuangan air (drainase). Selanjutnya, media tanam lain seperti pakis, dan serabut kelapa dapat membantu tanaman anggrek dapat tumbuh dengan baik pada saat ditanam dan sesuai dengan kebutuhan tanam anggrek jenis Dendrobium sp.

Limbah adalah suatu buangan yang dihasilkan dari proses hasil produksi industri manupun rumah tangga. Limbah cair industri tidak semuanya memberikan dampak yang positif bagi tanaman. Limbah cair jika tidak diolah dengan baik, maka akan menimbulkan dampak yang negatif bagi tanaman. "Pupuk limbah industri sebelum dimanfaatkan harus melalui proses pengolahan limbah dengan maksud menurunkan suhu limbah $\mathrm{pH}$ maupun pengaruh negatif bahan beracun bahaya (B3), seperti logam berat” (Anwar dan Suganda, 2006).

Rizqiani (2007) menyatakan bahwa "pemberian pupuk organik cair harus memperhatikan konsentrasi atau dosis yang diaplikasikan terhadap tanaman”. Saat memberikan pupuk cair harus memperhatikan dosis yang akan diberikan kepada tanaman, agar unsur-unsur hara yang didapatkan oleh tanaman tersebut tidak kekurangan dan juga tidak berlebihan sehigga dapat mengoptimalkan pertumbuhan tanaman.

Ilmu pengetahuan biologi akan selalu berkembang seiring dengan perkembangan zaman, hal ini dikarenakan manusia selalu memiliki rasa ingin tahu yang sangat besar dalam diri setiap manusia yang selalu ditunjang dengan selalu berkembangnya ilmu pengetahuan dan teknologi. 
Juhri (2009) menyatakan bahwa kegiatan belajar akan lebih berhasil, jika orang yang belajar itu aktif di dalamnya dengan cara mengalami, berbuat dan memberikan reaksi. Belajar akan lebih berhasil, apabila seluruh diri orang yang ikut belajar ikut serta aktif.

Siswa dituntut untuk melakukan suatu praktek mengenai cara penanaman anggrek yang akan mengamati proses pertumbuhan tanaman tersebut, dimana nantinya diharapkan dari diri siswa akan tumbuh sikap-sikap ilmiah dan peka terhadap kondisi di lingkungan sekitar sebagai wujud pembelajaran yang PAIKEM (Pembelajaran yang Aktif, Inovatif, Kreatif dan Menyenangkan).

Purwaningsih (2014) menyatakan bahwa karakter adalah watak, tabiat, akhlak, atau kepribadian seseorang yang terbentuk dari hasil internalisasi berbagai kebijakan (virtues) yang diyakini dan digunakan sebagai suatu landasan untuk cara pandang, berfikir, bersikap dan bertindak. Kebijakan-kebijakan yang akan dilihat dari karakter tersebut diantaranya seperti kebijakan dalam sejumlah nilai, moral dan norma yang diantaranya seperti sifat jujur, berani bertindak, dapat dipercaya, dan hormat kepada orang lain.

Materi yang tepat untuk penelitian adalah pada materi Pertumbuhan dan Perkembangan, pada materi ini akan lebih optimal jika siswa dilibatkan langsung dalam metode percobaan atau eksperimen ataupun praktikum. Menurut Purwaningsih (2013) bahwa secara garis besar praktikum sering dikaitkan dengan beberapa tujuan dalam pembelajaran diantaranya:

1. Digunakan untuk memotivasi siswa yang pada umumnya kegiatan praktikum itu dapat menarik siswa dalam melakukan proses pembelajaran sehingga dapat memotivasi siswa untuk belajar sains.

2. Untuk mengajarkan keterampilan dasar ilmiah kepada siswa.

3. Untuk meningkatkan pemahaman siswa tentang konsep dari pembelajaran yang dilakukan.

4. Untuk membantu siswa dalam memahami dan menggunakan metode ilmiah yang baik dan benar, dan

5. Untuk mengembangkan dan menumbuhkan sikapsikap ilmiah dari diri siswa didik.

Sumber belajar dalam penelitian ini dirancangkan digunakan guru salah satunya adalah panduan praktikum pada Biologi SMA kelas XII semester ganjil dengan Kompetensi Inti (KI) dengan melakukan percobaan Pertumbuhan dan Perkembangan pada Tumbuhan, dengan Kompetensi Dasar (KD) melaksanakan percobaan pengaruh faktor luar terhadap pertumbuhan tanaman.

\section{Metode Penelitian}

Penelitian menggunakan metode eksperimen desain RAL (Rancangan Acak Lengkap) dengan perlakuan terdiri 3 perlakuan dosis yang berbeda $(2 \mathrm{ml}, 3 \mathrm{ml}$ dan $4 \mathrm{ml})$ dan I kontrol dengan 8 kali ulangan. Parameter yang diamati terdiri pertumbuhan tinggi tanaman $(\mathrm{cm})$ dan pertambahan jumlah daun (helai) tanaman anggrek Dendrobium sp. Proses dan hasil penelitian kemudian disusun untuk proses pembelajaran pada saat praktikum (eksperimen) di sekolah.

\section{Hasil dan Pembahasan}

Pengaruh Pemberian Variasi Dosis terhadap Pertumbuhan Tinggi Tanaman Anggrek Dendrobium sp.

Penelitian pengaruh pemberian variasi dosis pupuk cair organik LCN Limbah Cair Nanas (LCN) terhadap pertumbuhan tanaman anggrek Dendrobium sp dengan parameter yaitu tinggi tanaman dan banyaknya jumlah daun, diamati setiap minggu selama 5 bulan (Juli sampai dengan Nopember) 2014.

Hasil pengamatan tinggi tanaman anggrek Dendrobium sp. disajikan pada Gambar I.

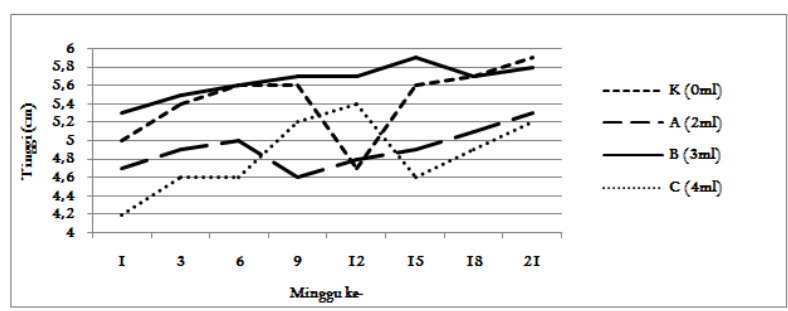

Gambar I. Diagram Rata-rata Tinggi (cm) Anggrek Dendrobium sp.

Dilihat dari rata-rata pertumbuhan tinggi $(\mathrm{cm})$ tanaman anggrek Dendrobium sp pada perlakuan B (3ml) lebih cepat pertumbuhannya dibandingkan dengan perlakuan lainnya, namun perbedaan tinggi tanaman tidak berbeda nyata $(\mathrm{p}<0,05)$.

Pertumbuhan Rata-rata Jumlah Daun (Helai) Tanaman Anggrek Dendrobium sp pada Gambar 2 berikut.

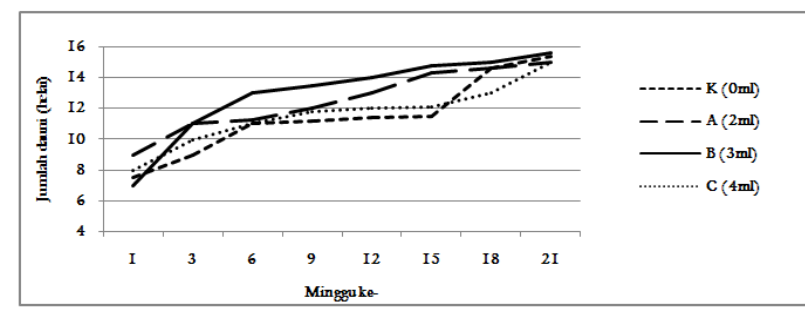

Gambar I. Diagram Rata-rata Jumlah daun (helai) Anggrek Dendrobium sp.

Berdasarkan gambar di atas, rata-rata jumlah daun tanaman anggrek Dendrobium sp mengalami pertumbuhan dan perkembangan pada setiap perlakuan yang diberikan. Jumlah daun lebih besar diperlihatkan pada perlakuan B dibandingkan dengan 3 perlakuan lainnya dan menunjukkan bahwa pertumbuhan dan perkembangan pada perlakuan ini lebih baik banyak dan berbeda nyata $(\mathrm{p}>0,05)$.

Pupuk cair LCN (Limbah Cair Nanas) yang digunakan merupakan limbah cair yang berasal dari limbah nanas yang telah melalui proses yang sedemikian rupa sehingga dapat menjadi pupuk organik yang 
bermanfaat bagi tanaman yaitu dengan proses bioremediasi. Bioremediasi merupakan suatu proses yang bertujuan untuk memperbaiki kondisi pencemaran yang terdapat di limbah tersebut dengan menggunakan bantuan beberapa macam organisme, sehingga dapat mengubah zat-zat yang berbahaya (toksik) untuk menjadi zat yang tidak berbahaya jika digunakan bagi lingkungan sekitar.

Isolasi limbah mampu meningkatkan keberadaan mikroorganisme berupa bakteri-bakteri indigen, dimana bakteri indigen tersebut diantaranya Bacillus cereus, Actinobacter baumani, Bacillus subtitlis dan Pseudomonas pseudomallei. Bakteri indigen ini mampu menetralkan $\mathrm{pH}$ dan memiliki potensi sebagai pengurai. Pengolahan limbah cair LCN (Limbah Cair Nanas) dapat memenuhi syarat standar baku mutu sebagai pupuk organik yang dapat digunakan sebagai pengganti pupuk kimia dan baik bagi tanaman.

Pertumbuhan tanaman anggrek pada penelitian ini menunjukkan bahwa pemberian pupuk cair LCN (Limbah Cir Nanas) sebanyak 0ml, 2ml, 3ml, dan 4ml memberikan pengaruh terhadap pertumbuhan tinggi dan jumlah daun. Dosis pupuk cair LCN yang menunjukkan pengaruh yang paling baik adalah pada dosis $3 \mathrm{ml}$. Pada pemberian dosis $3 \mathrm{ml}$ pupuk cair LCN pertambahan jumlah daun anggrek Dendrobium sp lebih cepat dan lebih banyak dibandingkan dengan dosis pupuk cair yang lainnya. Hal ini disebabkan nutrisi berupa unsur hara makro dan mikro yang berasal dari pupuk cair LCN (Limbah Cair Nanas) hasil dari proses bioremediasi yang dibutuhkan oleh tanaman anggrek Dendrobium sp tercukupi dengan baik dan seimbang. Tanaman anggrek merupakan tanaman yang membutuhkan unsur hara makro dan mikro yang seimbang, jika unsur hara yang diberikan tersebut kurang maka pertumbuhan tanaman anggrek akan terganggu, demikian pula sebaliknya jika tanaman anggrek diberikan unsur hara secara berlebih maka akan membuat tanaman anggrek menjadi cepat membusuk pada bagian batang dan ujung daunnya akan menguning.

Selain dari sifat-sifat fenotif dan genotif yang dapat mempengaruhi pertumbuhan dari tanaman anggrek ada pula beberapa karakter kuantitatif yang dapat diperhatikan dalam melakukan pembudidayaan tanaman adalah dengan memperhatikan jumlah daun, tinggi tanaman, diameter perbesaran pseudobulb, dan sebagainya. Kemudian pada karakter kualitatifnya dapat dilihat pada ketahanan tanaman terhadap penyakit, bentuk, corak dan warna dari bunga tanaman anggrek tersebut (Yusnita, 2012).

Pupuk cair LCN (Limbah Cair Nanas) yang digunakan dalam penelitian ini merupakan hasil dari proses bioremediasi. Bioremediasi merupakan proses yang dilakukan dengan memanfaatkan agen biologi yang dapat menetralkan $\mathrm{pH}$ dari Limbah Cair tersebut, bahkan agen biologi ini mampu mengubah bahan berbahaya yang tercemar di dalam limbah cair nanas tersebut menjadi bahan yang tidak berbahaya lagi terhadap tanaman dan lingkungan jika digunakan sebagai pupuk, agen biologi ini dapat berupa mikroba atau enzim. Pupuk cair LCN (Limbah Cair Nanas) yang digunakan dalam penelitian ini adalah limbah yang telah mengalami proses bioremediasi dengan memanfaatkan agen biologi berupa mikroba sehingga limbah cair ini dapat menjadi pupuk organik yang baik bagi tanaman.

\section{Pemanfaatan proses dan produk penelitian sdbagai sumber belajar}

Pemanfaatan hasil penelitian sebagai sumber belajar biologi berupa panduan praktikum. Panduan praktikum dibuat agar mempermudah siswa dalam melakukan kegiatan praktikum. Pada kurikulum 2013 maka kegiatan pembelajaran dituntut dengan kegiatan pendekatan ilmiah, kegiatan pendekatan ilmiah ini bertujuan agar siswa lebih aktif dan siswa mendapatkan pengalaman dalam kegiatan pembelajaran yang nyata sehingga dibuatlah panduan praktikum yang dapat membantu proses belajar siswa. Panduan praktikum yang dibuat ini hanya sebagai rancangan sumber belajar bagi siswa. Dalam panduan praktikum ini dibuat sampai pada tahap pengembangan kemudian dilakukan uji validasi oleh beberapa tim ahli yaitu tiga dosen dari Universitas Muhammadiyah Metro Jurusan Pendidikan Biologi.

Pada tahap perencanaan dimulai dari pembuatan analisis potensi sumber belajar yang dapat digunakan untuk menganalisis kebutuhan dan kemampuan siswa dalam melakukan kegiatan praktikum. Selanjutnya, pembuatan rancangan panduan praktikum yang meliputi teks, gambar, serta beberapa pertanyaan mendukung yang harus dikerjakan. Selanjutnya, produk akhir dari tahap pembuatan panduan praktikum ini adalah tersedianya teks dan gambar panduan praktikum biologi pada materi Pertumbuhan dan Perkembangan Kelas XII Semester I yang siap untuk diproses pada tahap berikutnya. Pada tahap berikutnya adalah mengembangkan panduan praktikum berdasarkan dengan produk akhir dari rancangan yang telah dibuat sehingga menjadi produk jadi berupa panduan praktikum.

Pengujian panduan praktikum dilakukan dengan meminta penilaian oleh ahli dengan cara membaca panduan praktikum kemudian mendata tanggapan ahli pada aspek kelayakan aspek materi pada panduan praktikum kelas XII SMA materi Pertumbuhan dan Perkembangan setelah membaca panduan praktikum yang telah disediakan. Pengujian panduan praktikum dilakukan oleh tiga oran ahli yaitu dosen dari Universitas Muhammadiyah Metro Program Studi Pendidikan Biologi. Adapun hasil dari penujian dari ketiga ahli untuk aspek materi dapat dilihat pada Tabel 2. 
Tabel 2. Hasil kelayakan Panduan Praktikum

\begin{tabular}{|c|c|c|c|c|c|c|}
\hline \multirow[b]{2}{*}{ No } & \multirow[b]{2}{*}{ Indikator Penilaian } & \multicolumn{3}{|c|}{ Skor \% } & \multirow[b]{2}{*}{-Rata-rata } & \multirow[b]{2}{*}{ Kriteria } \\
\hline & & Ahli I & Ahli 2 & Ahli 3 & & \\
\hline I & $\begin{array}{l}\text { Topik praktikum yang dibuat sesuai dengan Kompetensi Inti } \\
\text { (KI) dan Kompetensi Dasar (KD) SMA kelas XI }\end{array}$ & $80 \%$ & $80 \%$ & $80 \%$ & $80 \%$ & Baik \\
\hline 2 & $\begin{array}{l}\text { Topik praktikum yang dibuat menggambarkan keseluruhan } \\
\text { kegiatan praktikum yang akan dilakukan }\end{array}$ & $80 \%$ & $80 \%$ & $80 \%$ & $80 \%$ & Baik \\
\hline 3 & $\begin{array}{l}\text { Tujuan praktikum sudah sesuai dengan topik dan } \\
\text { menggambarkan apa yang akan dilakukan, diuji, dibuktikan, } \\
\text { atau apa yang akan dipelajari selama kegiatan praktikum } \\
\text { berlangsung }\end{array}$ & $80 \%$ & $60 \%$ & $80 \%$ & $73,3 \%$ & Baik \\
\hline 4 & $\begin{array}{l}\text { Dasar teori yang dibuat berisi materi yang berkaitan dengan } \\
\text { kegiatan praktikum }\end{array}$ & $60 \%$ & $80 \%$ & $80 \%$ & $73,3 \%$ & Baik \\
\hline 5 & $\begin{array}{l}\text { Dasar teori dapat dijadikan acuan siswa dalam kegiatan } \\
\text { praktikum }\end{array}$ & $80 \%$ & $80 \%$ & $100 \%$ & $86,7 \%$ & $\begin{array}{c}\text { Sangat } \\
\text { baik }\end{array}$ \\
\hline 6 & $\begin{array}{l}\text { Materi dalam dasar teori sudah sesuai dengan Kompetensi Inti } \\
\text { (KI) dan Kompetensi Dasar (KD) SMA Kelas XI }\end{array}$ & $80 \%$ & $80 \%$ & $80 \%$ & $80 \%$ & Baik \\
\hline 7 & $\begin{array}{l}\text { Alat dan bahan yang ditampilkan sesuai dengan tujuan } \\
\text { praktikum dan mempermudah siswa melakukan praktikum. }\end{array}$ & $100 \%$ & $80 \%$ & I00\% & $93,3 \%$ & $\begin{array}{c}\text { Sangat } \\
\text { baik }\end{array}$ \\
\hline 8 & $\begin{array}{l}\text { Cara kerja yang dibuat sesuai dengan tujuan dan berisi kegiatan } \\
\text { yang harus dilaksanakan siswa dalam praktikum }\end{array}$ & $80 \%$ & $80 \%$ & $80 \%$ & $80 \%$ & Baik \\
\hline 9 & $\begin{array}{l}\text { Cara kerja yang dibuat dapat membantu siswa dalam } \\
\text { melaksanakan praktikum }\end{array}$ & $80 \%$ & $80 \%$ & $80 \%$ & $80 \%$ & Baik \\
\hline \multirow[t]{2}{*}{10} & Pertanyaan yang dibuat sesuai dengan kegiatan praktikum & $60 \%$ & $60 \%$ & $100 \%$ & $73,3 \%$ & Baik \\
\hline & Rata & & & & $\begin{array}{c}79,99 \\
\%\end{array}$ & Baik \\
\hline
\end{tabular}

Berdasarkan hasil analisis angket dari para ahli oleh dosen mengenai panduan praktikum yang dikembangkan menghasilkan presentase sebesar 79,99\%. Hasil ini tergolong ke dalam kategori baik. Dengan demikian bahwa dapat disimpulkan dari segi materi, panduan praktikum yang dikembangkan layak untuk dijadikan sebagai panduan praktikum dalam kegiatan praktikum siswa.

\section{Simpulan}

Berdasarkan hasil penelitian yang telah dilakukan, dapat disimpulkan bahwa:

I. Pengaruh pemberian variasi dosis pupuk cair LCN (Limbah Cair Nanas) terhadap pertumbuhan tinggi tanaman anggrek Dendrobium sp. Tidak berbeda nyata.

2. Ada pengaruh nyata terhadap pemberian variasi dosis pupuk cair LCN (Limbah Cair Nanas) terhadap jumlah daun anggrek Dendrobium sp.

3. Dosis pupuk cair LCN (Limbah Cair Nanas) yang memberikan pengaruh terbaik terhadap pertumbuhan tanaman anggrek Dendrobium sp dalam hal ini jumlah daun (helai) adalah pada dosis pupuk cair LCN $3 \mathrm{ml}$.

4. Proses dan produk hasil penelitian dapat dijadikan sebagai rancangan sumber belajar biologi SMA kelas XII materi pokok Pertumbuhan dan Perkembangan dalam bentuk Panduan Praktikum.

\section{Daftar Pustaka}

Agromedia. 2006. Cara Cepat Merawat Anggrek. Jakarta: PT. AgroMedia Pustaka.

Anwar Ek dan Suganda. 2006. Pupuk Limbah Industri. (Online). balitanah.litbang.deptan.go.id. Diakses pada 29 Maret 2014.

Hanafiah, Kemas Ali. 20I0. Rancangan Percobaan Teori dan Aplikasi. Jakarta: Rajawali Press.

Juhri. 2009. Landasan Dan Wawasan Pendidikan. Jakarta: Panji Grafika.

Lestari, Sugeng Sri. 2003. Mengenal dan Menanam Anggrek. Semarang: Aneka Ilmu.

Purwaningsih, Ika Yunita. 2014. Pengembangan Petunjuk Praktikum Biologi Ilustratif Berbasis Pendekatan Inkuiri Terbimbing (Guidea Inquiry) yang Mengembangkan Pendidikan Karakter pada Materi Pokok Sistem Pencernaan Makanan untuk Kelas XI Semester I di SMA Muhammadiyah 3 Yogyakarta. Disertasi. Yogyakarta: Program Sarjana Universitas Islam Negeri Sunan Kalijaga Yogyakata.

Rizqiani. 2007. Pengaruh Dosis dan Frekuensi Pemberian Pupuk Cair terhadap Pertumbuhan dan Hasil Buncis (Phaseolus vulgaris L.) Dataran Rendah. Jurnal Ilmu Tanah dan Lingkungan Vol. 7 no. I p: 43-53.

Sutanto, Agus. 20I I. Degradasi Bahan Organik Limbah Cait Nanas oleh Bakteri Indigen. El-hayah vol. I, no. 4 maret 20 I I page I5I of I56.

Yusnita. 20I2. Pemuliaan Tanaman untuk Menghasilkan Anggrek Hibrida Unggul. Bandar Lampung: Lembaga Universitas Lampung. 